\title{
Explanations for 20th Century Tuberculosis Decline: How the Public Gets It Wrong
}

\author{
Ray M. Merrill, Spencer S. Davis, Gordon B. Lindsay, Elena Khomitch \\ Department of Health Science, College of Life Sciences, Brigham Young University, Provo, USA \\ Email: Ray_Merrill@byu.edu
}

How to cite this paper: Merrill, R.M., Davis, S.S., Lindsay, G.B. and Khomitch, E. (2016) Explanations for 20th Century Tuberculosis Decline: How the Public Gets It Wrong. Journal of Tuberculosis Research, 4, 111-121. http://dx.doi.org/10.4236/jtr.2016.43014

Received: May 13, 2016

Accepted: August 23, 2016

Published: August 26, 2016

Copyright $\odot 2016$ by authors and Scientific Research Publishing Inc. This work is licensed under the Creative Commons Attribution International License (CC BY 4.0).

http://creativecommons.org/licenses/by/4.0/ (c) (7) Open Access

\begin{abstract}
Introduction: Historical analysis of health data indicates that the majority of the decrease in tuberculosis mortality during the past century was caused by improved social conditions and public health interventions. The purpose of this study was to assess lay public perceptions regarding why tuberculosis declined. Materials and Methods: A nationally representative sample of 705 adults was surveyed to identify their perceived reasons for the decline in tuberculosis mortality in the 20th century. Openended questions and responses were coded and placed into eight categories. Results: Approximately $52 \%$ of decreasing tuberculosis mortality was attributed to "modern medicine," and $220 \%$ to "vaccination." Comparatively few of the respondents attributed decreased tuberculosis mortality rates to public health or improvements in social health determinants of health. Males gave more credit to modern medicine and public health, with less to vaccination; the other racial group gave more credit to public health and less to modern medicine; Hispanics gave more credit to modern medicine and less to vaccinations; and the higher income groups gave more credit to vaccinations and public health, but less to modern medicine. Conclusion: The public overly attributes modern medicine as the primary cause of declining tuberculosis mortality rates, the second leading cause of death in the United States during the early 1900s, and gives little credit to the critical role played by public health and improved social conditions. These misperceptions may hinder societal efforts to address and fund important social determinants of health and public health interventions.
\end{abstract}

\section{Keywords}

Public Health, Tuberculosis, Mortality Rate, Medicine

\section{Introduction}

Effective national health policy must be based on a correct understanding of health 
determinants. A recent study demonstrated that the general public attributes most of the 40 year increase in life expectancy during the last 200 years to improvements in medical care [1]. However, officials in public health estimate less than a quarter of that improved life expectancy can be attributed to the medical sector [2]. Public health efforts involving improved food production, water safety, sewage treatment, housing, literacy, economics, and safer working conditions explain most of the increase [3]. The current study provides a second reference point by determining if people also primarily credit modern medicine for the decline seen in tuberculosis mortality over the past century. In the United States in 1900, this infectious disease was a leading cause of death, explaining $11.3 \%$ of all deaths, just behind pneumonia and influenza, which accounted for $11.8 \%$ of all deaths [4]. If people attribute the decline in tuberculosis to the medical sector, it reinforces the argument that the public is unaware that the most important health determinants are often found outside of hospital walls.

The purpose of this study was to determine how the general public explains the historical decline of tuberculosis mortality. This disease was selected for study because of its high ranking cause of death in the early 1900s, and, along with other infectious diseases, because it motivated and was directly impacted by non-medical public health efforts for more than a century. If society fails to appreciate the important role nonmedical interventions played in reducing past infectious diseases, it is likely to continue to attribute modern medicine as the primary vehicle to improve contemporary population health. Conversely, people will be less likely to support public health interventions or policies that seek to improve population health by addressing health disparities and circumstances shaping health by the distribution of money, education, power and resources (social determinants of health).

\section{Background}

Tuberculosis (TB) is an infectious bacterial disease caused by Mycobacterium tuberculosis. It generally affects the lungs or throat, is spread through the air when a person with TB talks, sneezes, or coughs, and has been a leading cause of death throughout history. Known historically as consumption, phthisis, or the white death, TB has been found in bodies dated as early as $5000 \mathrm{BC}$ and in Egyptian mummies dated to $3000 \mathrm{BC}$ [5] [6]. Hippocrates and other ancient physicians described the symptoms of the disease when they saw them among their patients [6]-[8]. During the 17th century, tuberculosis was a common killer, especially in England where one in five deaths were tubercular. The disease became endemic throughout Europe, resulting in its infamous appellation, the Great White Plague [5].

Tuberculosis mortality rates in western countries began to fall long before any medical intervention was discovered, and even before the implementation of anti-tuberculosis public health campaigns in the 18th and 19th centuries [9]. To a degree, this progressive decline through history can be attributed to the disease's natural epidemic cycle that ebbs and flows [10]. In the United States, the disease peaked in the mid to late 1800s and the subsequent fall was hastened by human interventions [9] [10]. 
The cause of tuberculosis was identified in 1882 with the discovery of tubercle bacillus by the German scientist, Robert Koch [11]. Koch also described the tuberculin reaction in 1890 [11]. In 1900, tuberculosis was the second leading cause of death in the United States with an annual crude mortality rate of 194.4 deaths per 100,000 [9]. By 1940 , before the introduction of antibiotics, the death rate was reduced to 46 deaths per 100,000 [10]. Figure 1 illustrates that the vast majority of this reduction occurred before 1944 when streptomycin, the first effective antibiotic for tuberculosis, was developed [4] [12] [13]. The only significant historical difference between these countries was that the British National Health Service began to use the BCG vaccine, an innovation that the United States Public Health Service has never embraced [14]-[16]. Even with the use of the BCG vaccine in England and Wales, and the use of streptomycin in the United States, there was not a significant change in the rate of decline of tuberculosis deaths [6]. Because the BCG vaccine was never universally put into practice in the United States, it can be said that none of the decline in incidence or death rates can be attributed to vaccine use.

Similarly, since streptomycin was the first antibiotic available to treat tuberculosis, it can also be said that none of the decline prior to 1944 was attributable to antibiotics. However, it is not accurate to conclude that all the reduction in mortality after 1944 is attributed solely to the development of an effective drug. The same forces driving the decline of tuberculosis prior to the development of streptomycin continued to operate

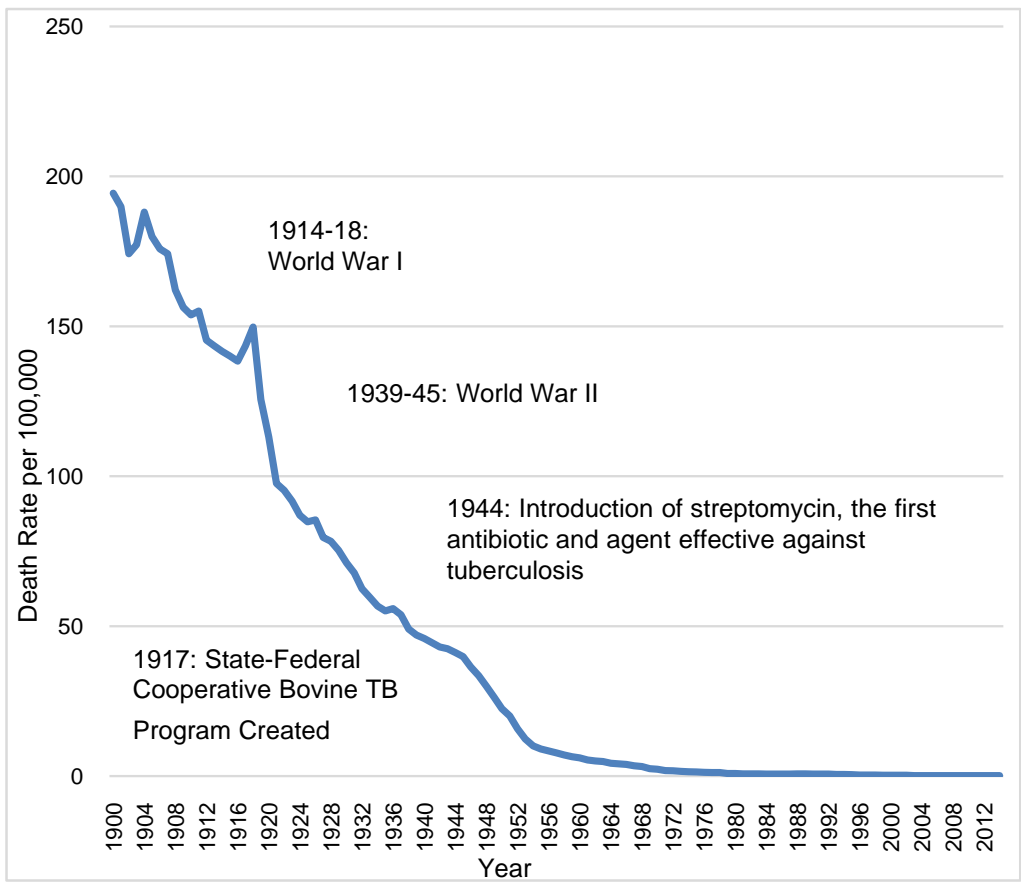

Figure 1. Crude death rates for tuberculosis in the United States, 1900-2014. Note that with the exception of the period during World War I, rates of death by tuberculosis in the United States were falling long before the advent of antibiotic treatments. Aggressive policies to combat bovine tuberculosis, state mandated sanatoria, and improvements in housing all contributed to the decline. The decline of tuberculosis in the United States is similar to that in England and Wales. 
in ensuing years and should be credited for much of the continued decline.

Mycobacterium tuberculosis is most commonly known for its pulmonary strain and the infecting agent that travels through airborne droplets. Airborne communicability is facilitated in overcrowded and poor housing conditions. Studies done in the early part of the 20th century noted the link between housing conditions and tuberculosis prevalence [3] [17]. Overcrowded urban areas in the late 1800's and early 1900's facilitated the spread of tuberculosis. In Massachusetts prisons, where prisoners were kept in very close proximity, three-quarters of all deaths between 1890 and 1895 were caused by tuberculosis [6]. Health education programs beginning as early as 1889 promoted improved housing conditions, personal hygiene, and overall cleanliness, as well as instruction on how to properly sneeze and cough and against spitting in public [3] [9] [10]. Contemporary analyses of spatial tuberculosis incidence continue to support the association between poor housing, living conditions, proper ventilation, improper sanitation, and overcrowding with higher tuberculosis incidence rates [7] [8] [18].

Studies conducted in the 20th and 21st centuries have shown a relationship between nutritional status and tuberculosis risk, especially with regard to malnutrition negatively affecting the immune system. Malnourishment facilitates tuberculosis contraction by reducing the response of macrophages, T-lymphocytes, and cytokines involved in cell-mediated immunity, which acts as the primary defense against the tubercle bacilli, as well as promoting secondary immunodeficiency [8] [19] [20]. Tuberculosis is an opportunistic disease; when an immune system has been weakened from the effects of malnutrition, the susceptibility of tuberculosis infection increases as does the risk of mortality [21]. Improvements made in the early 20th century such as safe food handling, production, transportation, availability of food, and the discovery of essential nutrients and their role in disease prevention all contributed to reducing malnutrition within the United States. Improved nutritional status greatly reduced tuberculosis mortality rates [22] [23].

Social isolation of active cases from the general population through the use of sanatoria also played a role in tuberculosis decline. While early sanatoria acted as little more than hotels for the rich or places to corral the poor infected with tuberculosis, procedures improved over time to increase recovery rates and promote prevention [24]. Hygiene instruction in the sanatoria played a role by reducing transmission with practices such as covering the mouth when sneezing or coughing, and limiting where people could openly spit [25]. Guests and patients were asked not to shake hands or have other physical contact with patients to prevent spreading the disease; the creation of dust-free environments with clean floor space and good ventilation was also a priority in sanatoria [25].

Besides the more common pulmonary strain, the less well-known bovine tuberculosis strain contributed to a significant number of tuberculosis cases. It is estimated that bovine tuberculosis was responsible for $15 \%$ of all tuberculosis deaths in 1900, as well as a third of all non-pulmonary cases [8] [26]. After discovering that the bacteria was spread by consuming contaminated meat and milk, the United States implemented 
policies that mandated milk pasteurization and identified sick cattle using tuberculin tests, and their subsequent destruction. These measures nearly eradicated bovine tuberculosis transmission and resulted in the prevention of over 25,000 deaths preceding World War II [27].

The development of the antibiotic drug streptomycin in 1944 and its subsequent use gave physicians a powerful tool to combat active tuberculosis cases. It is important to note that vaccinations, which played a major role in eliminating many infectious diseases, played no role in preventing tuberculosis in the United States. Health officials in this country opted not to use the Bacille Calmette-Guerin (BCG) vaccination because it makes detecting latent tuberculosis cases more difficult [28]. While antibiotics helped to decrease tuberculosis mortality in the 20th Century, it was improved public health interventions, that started over 100 years ago, which had the greatest effect. Overlooking the contributions of the social determinants of health and the public health's historical role in mortality decline may lead to creating health policies that rely too heavily on medicine as the primary way to improve population health. By giving most or all of the credit to modern medicine, contemporary efforts to address social determinants of health and public health interventions, which have a greater ability to improve population health, are likely to be neglected and underfunded. Misattribution of credit may also contribute to overfunding the medical sector of the economy and impede efforts to contain health care costs.

\section{Methods}

A questionnaire was developed to determine what factors the public believed caused the historical reductions of tuberculosis mortality rates in the United States. Results are based on responses to the following: "In the United States in 1900, 11.3\% of all deaths were attributed to Tuberculosis." In 2000, less than $1 \%$ of all deaths in this country were attributed to Tuberculosis. What do you think is the primary reason for the decrease? Possible responses that the respondents selected were medicine, vaccines/immunizations, sanitation, screening/quarantine, lifestyle, education/awareness/knowledge, other, or don't know. Thirty individuals selected don't know. Three public health faculty not involved in the study evaluated the instrument for content and face validity. The questionnaire was revised and then tested on a convenience sample of twenty individuals who were thought to accurately represent the population of the United States. The instrument was again revised and pilot tested on 357 public health students. Results from this pilot study supported the hypothesis that the majority of people would attribute the decline in tuberculosis mortality to medical care, and provided inputs in the sample size calculation. Approval to conduct human subject research was obtained from the investigator's Institutional Review Board prior to conducting the pilot testing and subsequent national administration of the survey.

The survey utilized an open ended question to measure how people explained the decline in tuberculosis mortality in the 20th century. Participants were informed that in 1900, tuberculosis was the second leading cause of death in the United States and that 
its death rates declined by over 90\% between 1900 and 1950 [4]. Participants were asked to briefly describe the single most important reason for the decline. If they gave more than one answer, then their first answer was assumed to be the most important.

Two researchers independently read through the responses to the open ended question, then placed and coded them into eight categories: (1) modern medicine (i.e. healthcare, physicians, hospitals, surgeries, diagnostic techniques, antibiotics, etc.), (2) vaccination, (3) education/awareness/knowledge, (4) lifestyle, (5) sanitation, (6) screening/quarantine, (7) don't know, and (8) other. Coding for each open ended response was compared, and the few discrepancies that existed were resolved through discussion and then mutual agreement.

Demographic data was collected to analyze potential differences in responses between groups and to ensure that a representative national sample had been drawn. Variables included age, sex, race, ethnicity, and education.

Survey data was gathered from an online sample of actively managed panels of respondents who had been recruited by a national professional public opinion/marketing research company [29]. The online sample involved respondents from the United States ages 18 years or older. The company's reward system engaged and motivated participation and encouraged better representation. Participants who have an interest in contributing to research were incentivized to be members of the company's response panels. The strict quality control procedures used by the company's recruiting practices ensures that samples of opt-in respondents are of high quality. The demographics of potential respondents were known to the research company before an invitation to participate was extended. The opportunity to complete the survey was progressively closed to some individuals after select demographic variables were sufficiently represented in the sample. This procedure ensured that the generated sample was representative of the United States national demographic profile with respect to age, sex, race (White/Caucasian, Black/African American, Other), ethnicity (Hispanic, non-Hispanic), annual household income ( $<\$ 25 \mathrm{~K}, \$ 25 \mathrm{~K}-\$ 49 \mathrm{~K}, \$ 50 \mathrm{~K}-\$ 74 \mathrm{~K}, \geq \$ 75 \mathrm{~K}$ ), and education (some high school, high school or GED, some college or technical school, college graduate, master's degree, doctoral or professional degree). A total of 725 individuals completed the survey. Quality assurance methods were used to identify nonsensical survey responses. Twenty such responses were eliminated from the analysis, resulting in a final sample size of 705 .

Frequency distributions were used to summarize and describe the data. Bivariate analyses were used to evaluate the relationship between selected variables, with the chisquare test used to evaluate significance. The Mantel-Haenszel ( $\mathrm{MH}$ ) chi-square was also used to evaluate differences in trend. Two-sided tests of hypotheses were evaluated using the 0.05 level of significance. Analyses were performed using the Statistical Analysis System (SAS) software, version 9.3 (SAS Institute Inc., Cary, NC, USA, 2010).

\section{Results}

Distributions of age, sex, race, ethnicity, education, and income are presented in Table 1. The most common single response to the open-ended question for why tuberculosis 
declined during the 20th century was "modern medicine," followed by "vaccination," and then selected public health choices (Table 2). The high degree of attribution given to modern medicine for causing the declines in tuberculosis mortality was significantly associated with sex, race, ethnicity, and income. Males gave more credit to modern medicine and public health, with less to vaccination; the other racial group gave more

Table 1. Summary of participant characteristics.

\begin{tabular}{|c|c|c|}
\hline & No. & $\%$ \\
\hline \multicolumn{3}{|l|}{ Age (years) } \\
\hline $18-29$ & 159 & 23 \\
\hline $30-39$ & 146 & 21 \\
\hline $40-49$ & 140 & 20 \\
\hline $50-59$ & 138 & 20 \\
\hline $60-69$ & 90 & 13 \\
\hline $70+$ & 32 & 5 \\
\hline \multicolumn{3}{|l|}{ Sex } \\
\hline Male & 344 & 49 \\
\hline Female & 361 & 51 \\
\hline \multicolumn{3}{|l|}{ Race } \\
\hline White/Caucasian & 599 & 85 \\
\hline Black/African American & 59 & 8 \\
\hline Other & 47 & 7 \\
\hline \multicolumn{3}{|l|}{ Ethnicity } \\
\hline Latino/Hispanic & 57 & 8 \\
\hline Not Latino/Hispanic & 645 & 91 \\
\hline Don't Know/Not Sure & 3 & 0 \\
\hline \multicolumn{3}{|l|}{ Annual Household Income } \\
\hline$<\$ 25 \mathrm{~K}$ & 171 & 24 \\
\hline$\$ 25 \mathrm{~K}-\$ 49 \mathrm{~K}$ & 218 & 31 \\
\hline$\$ 50 \mathrm{~K}-\$ 74 \mathrm{~K}$ & 140 & 20 \\
\hline$\geq \$ 75 \mathrm{~K}$ & 176 & 25 \\
\hline \multicolumn{3}{|l|}{ Education } \\
\hline Some High School & 15 & 2 \\
\hline High School Graduate or GED & 151 & 21 \\
\hline Some College or Technical School & 282 & 40 \\
\hline College Graduate & 177 & 25 \\
\hline Master's Degree & 64 & 9 \\
\hline Doctoral or Professional Degree & 16 & 2 \\
\hline
\end{tabular}

GED: General education development test. 
Table 2. Primary reasons given why tuberculosis declined in the United States, from causing $11.3 \%$ of all deaths in 1900 to less than $1 \%$ in 2000 .

\begin{tabular}{cccccccccccccc}
\hline & & & Male & Female & White & Black & Other & Hispanic & Non-Hispanic & $<25 \mathrm{~K}$ & $25 \mathrm{~K}-49 \mathrm{~K}$ & $50 \mathrm{~K}-74 \mathrm{~K}$ & $\geq 75 \mathrm{~K}$ \\
\hline & No. & $\%$ & $\%$ & $\%$ & $\%$ & $\%$ & $\%$ & $\%$ & $\%$ & & \\
Modern medicine & 352 & 52 & 55 & 50 & 53 & 52 & 38 & 58 & 52 & 57 & 58 & 50 & 42 \\
Vaccination & 151 & 22 & 16 & 28 & 23 & 21 & 16 & 17 & 23 & 16 & 23 & 25 & 26 \\
Other & 172 & 26 & 29 & 22 & 24 & 27 & 47 & 25 & 25 & 27 & 19 & 25 & 32 \\
\hline
\end{tabular}

Note that the primary reasons given significantly differed between males and females (Chi-square $p=0.0004)$, among racial groups $(p=0.0198)$, between Hispanics and non-Hispanics $(\mathrm{p}=0.0441)$, and among income groups $(\mathrm{p}=0.0088) ;{ }^{\star} 59(8 \%)$ that indicated education/awareness/knowledge, $33(5 \%)$ that indicated sanitation, $25(4 \%)$ that indicated screening or quarantine, $12(2 \%)$ that indicated lifestyle, and $43(6 \%)$ that indicated another choice (no category).

credit to public health and less to modern medicine; Hispanics gave more credit to modern medicine and less to vaccinations; and the higher income groups gave more credit to vaccinations and public health, but less to modern medicine. Reasons as to why tuberculosis declined did not significantly differ across age or levels of education.

\section{Discussion}

The public's perception that medical procedures played the predominant role in reducing tuberculosis mortality is strongly contradicted by the historical record (see Figure 1). The decline in tuberculosis mortality in the developed world has resulted mostly from improved living conditions and not because of modern medicine [5]. Most of the decline occurred before the advent of an effective antibiotic treatment, and did not decline at an increasing rate after its creation. The fact that $22 \%$ of respondents identified vaccination as the primary reason for the historical reduction, even though the United States never used the BCG vaccine, highlights the public's unawareness surrounding factors that have reduced the burden of infectious disease. Only a small number of people mentioned the role played by environmental improvements, better housing, sanitation, improved nutrition, or other factors related to public health or the social determinants of health. It is likely that the public would have similar misperceptions regarding why polio, measles, cholera, typhoid and other infectious disease mortality declined.

There are several possible explanations for this misdirected credit for the decline in tuberculosis mortality. First, many of the public health interventions that were implemented to combat tuberculosis were established over 100 years ago, and have been forgotten with the passage of time. Interventions that were established to reduce tuberculosis mortality such as better housing, ventilation, proper hygiene, and balanced nutrition, have continued to improve-becoming part of everyday life for most segments of the population. Contributing to this public forgetfulness is the fact that people today do not live in a time when infectious diseases are a major problem.

Media and television may also contribute to the public's misperceptions for declines in infectious disease. Medical dramas rarely draw attention to the contributions of environmental health, better nutrition, or the effects of poverty and other social deter- 
minates of health as contributing factors to disease. Television programs based in hospital settings focus on treatments and individual patient care, and may lead people to believe that modern medicine can cure anything and solutions can always be found in the hospital. Other media formats, such as the news, also focus on the latest medical technological development rather than the less exciting issues of public health interventions and social determinants of health.

The misperceptions identified in this study have implications for national health policy. Efforts to improve the nation's health in a democratic society are strongly influenced by the public's belief that interventions are effective. When people are unaware of the major role that non-medical health interventions play in reducing leading causes of death, they will be less likely to support contemporary endeavors that address these non-medical factors. Conversely, when people perceive that modern medicine is the primary reason why the nation strongly reduced leading causes of death, they may be suspicious and unsupportive of societal efforts to curtail the overuse of expensive medical technology and redirect resources to other health determinants.

It may be that the percentage of respondents who believed that modern medicine has played the predominant role in reducing tuberculosis mortality is underreported by the "modern medicine" category in this study. Many of the respondents who listed "education" or "awareness" or "knowledge" as the reason for the decline could have been thinking how these factors improved medical procedures. Giving too much credit to modern medicine for past public health achievements may contribute to the United States spending almost twice as much per capita on health care as other high income Western nations. Public misattribution of credit may also partially explain why the United States neglects funding public health initiatives and fails to address the social determinants of health. Research shows that the United States increasingly lags behind other countries in life expectancy as other nations more fully address the social service needs of the population [30]. Given that almost a fifth of the national gross domestic product is spent on healthcare, it is difficult to find resources to address healthenhancing social service needs.

\section{Conclusion}

This study identified the general public's perceived reasons for the historical decline of tuberculosis mortality. We hypothesized that greater attribution for the decline would be given to modern medicine non-medical interventions played in reducing past infectious diseases. Results showed that the public has a strong medical-centric explanation for decreases in tuberculosis. As such, people may be less inclined to support public health interventions or policies that seek to improve population health.

\section{Acknowledgements}

This research was funded through the Department of Health Science, Brigham Young University (BYU). The views expressed are those of the authors and not necessarily those of BYU. 


\section{Conflict of Interest}

The authors declare they have no competing interests.

\section{References}

[1] Lindsay, G.B., Merrill, R.M. and Hedin, R.J. (2014) The Contribution of Public Health and Improved Social Conditions to Increase Life Expectancy: An Analysis of Public Awareness. Journal of Community Medicine and Health Education, 4, 5.

[2] Frieden, T.R. (2015) The Future of Public Health. The New England Journal of Medicine, 373, 1748-1754. http://dx.doi.org/10.1056/NEJMsa1511248

[3] Vynnycky, E. and Fine, P. (1999) Interpreting the Decline in Tuberculosis: The Role of Secular Trends in Effective Contact. International Journal of Epidemiology, 28, 327-334. http://dx.doi.org/10.1093/ije/28.2.327

[4] Data from Center for Disease Control and Prevention. Leading Causes of Disease, 19001998. http://www.cdc.gov/nchs/data/statab/lead1900 98.pdf

[5] Ryan, F. (1994) The Reign of Terror. The Forgotten Plague: How the Battle against Tuberculosis was Won-and Lost. Little, Brown and Company, New York.

[6] Daniel, T.M. (1999) Captain of Death, the Story of Tuberculosis, University of Rochester Press, Rochester, New York.

[7] Levy, S. (2012) The Evolution of Tuberculosis. Bioscience [Serial Online], 62, 625-629. http://dx.doi.org/10.1525/bio.2012.62.7.3

[8] Dormandy, T. (2000) The White Death: A History of Tuberculosis. New York University Press, New York.

[9] Dubos, R. and Dubos, J. (1952) The White Plague: Tuberculosis, Man, and Society. 3rd Edition, Little, Brown and Company, Boston.

[10] Center for Disease Control and Prevention (1999) Achievements in Public Health, 19001999: Control of Infectious Diseases. Morbidity and Mortality Weekly Report, 48, 621-629.

[11] Koch, R. (1882) Die Atiologic der Tuberkulose. Berliner Klinische Wochenschrift, 15, 221-230.

[12] Schatz, A. and Waksman, S. A. (1944) Effect of Streptomycin and Other Antibiotic Substances upon Mycobacterium Tuberculosis and Related Organisms. Experimental Biology and Medicine, 57, 244-248. http://dx.doi.org/10.3181/00379727-57-14769

[13] Center for Disease Control and Prevention (2015) Reported Tuberculosis in the United States, 2014. U.S. Department of Health and Human Services, CDC, Atlanta, GA.

[14] Stead, W.W. and Dutt, A.K. (1988) Epidemiology and Host Factors. In: Schlossberg, D., Ed., Tuberculosis, 2nd Edition, Springer-Verlag, New York, 1-11. http://dx.doi.org/10.1007/978-1-4684-0305-3

[15] Ryan, F. (1992) The Forgotten Plague: How the Battle against Tuberculosis Was Won-and Lost. Little, Brown and Company, New York.

[16] Luca, S. and Mihaescu, T. (2013) History of BCG Vaccine. Maedica [Serial Online], 8, 5358.

[17] Kass, E. (1971) Infectious Diseases and Social Change. The Journal of Infectious Diseases [Serial Online], 123, 110-114. http://dx.doi.org/10.1093/infdis/123.1.110

[18] Munayco, C.V., Mújica, O.J., León, F.X., del Granado, M. and Espinal, M.A. (2015) Social Determinants and Inequalities in Tuberculosis Incidence in Latin America and the Caribbean. Revista Panamericana de Salud Pública, 38, 177-185. 
[19] Clark, M., Riben, P. and Nowgesic, E. (2002) The Association of Housing Density, Isolation and Tuberculosis in Canadian First Nations Communities. International Journal of Epidemiology, 31, 940-945. http://dx.doi.org/10.1093/ije/31.5.940

[20] Smith, F.B. (1988) The Retreat of Tuberculosis 1850-1950. Croom Helm Ltd., Beckenham, Kent.

[21] Kant, S., Gupta, H. and Ahluwalia, S. (2015) Significance of Nutrition in Pulmonary Tuberculosis. Critical Reviews in Food Science and Nutrition, 55, 955-963. http://dx.doi.org/10.1080/10408398.2012.679500

[22] Rao, V.K., Iademarco, E.P., Fraser, V.J. and Kollef, M.H. (1998) The Impact of Comorbidity on Mortality Following In-Hospital Diagnosis of Tuberculosis. Chest, 114, 1244-1252. http://dx.doi.org/10.1378/chest.114.5.1244

[23] Gupta, K.B., Gupta, R., Atreja, A., Verma, M. and Vishvkarma, S. (2009) Tuberculosis and Nutrition. Lung India, 26, 9-16. http://dx.doi.org/10.4103/0970-2113.45198

[24] Centers for Disease Control and Prevention (1999) Achievements in Public Health, 19001999: Safer and Healthier Foods. Morbidity and Mortality Weekly Report, 48, 905-913.

[25] Philip, R. (1931) The Outlook on Tuberculosis: Changing Orientation. BMJ, 1, 43-49. http://dx.doi.org/10.1136/bmj.1.3653.43

[26] Pesanti, E. (1995) A History of Tuberculosis. In: Lutwick, L., Ed., Tuberculosis, Chapman \& Hall, London, 5-19. http://dx.doi.org/10.1007/978-1-4899-2869-6 2

[27] Olmstead, A. and Rhode, P. (2004) An Impossible Undertaking: The Eradication of Bovine Tuberculosis in the United States. The Journal of Economic History [Serial Online], 64, 734-772. http://dx.doi.org/10.1017/s0022050704002955

[28] Fairchild, A. and Oppenheimer, G. (1998) Public Health Nihilism vs Pragmatism: History, Politics, and the Control of Tuberculosis. American Journal of Public Health [Serial Online], 88, 1105-1117. http://dx.doi.org/10.2105/ajph.88.7.1105

[29] Survey Sampling International. https://www.surveysampling.com/

[30] Bradley, E.H., Elkins, B.R., Herrin, J. and Elbel, B. (2011) Health and Social Services Expenditures: Associations with Health Outcomes. BMJ Quality and Safety, 20, 826-831. http://dx.doi.org/10.1136/bmjqs.2010.048363

\section{Submit or recommend next manuscript to SCIRP and we will provide best service for you:}

Accepting pre-submission inquiries through Email, Facebook, LinkedIn, Twitter, etc. A wide selection of journals (inclusive of 9 subjects, more than 200 journals)

Providing 24-hour high-quality service

User-friendly online submission system

Fair and swift peer-review system

Efficient typesetting and proofreading procedure

Display of the result of downloads and visits, as well as the number of cited articles Maximum dissemination of your research work

Submit your manuscript at: http://papersubmission.scirp.org/ 